\title{
Dossier
}

\section{Redes intelectuales transnacionales: teoría, metodología e historiografía}

DOI: $10.25100 /$ hye.v13i49.5847

El presente monográfico en torno a redes intelectuales tiene tres ejes temáticos fundamentales. El primero de ellos es de carácter teórico-metodológico. El segundo está orientado a mostrar un balance historiográfico y el tercero constituye un estudio de caso. Cabe señalar que estos basamentos temáticos no son necesariamente fijos, por el contrario, hay vasos comunicantes entre ellos y en cada uno de los trabajos que componen el dossier; digamos que estos ejes temáticos son transversales a las cuatro investigaciones de este número de Historia y Espacio porque surgen de una preocupación compartida: entender cómo el estudio de las redes intelectuales permite conocer algunas dinámicas sociales del campo cultural latinoamericano en la primera mitad del siglo XX.

Como se sabe, es muy reciente en el medio historiográfico latinoamericano la historia intelectual que, progresivamente a partir de los años 1990 e incluso desde antes, ha venido sustituyendo a la historia de las ideas, evidentemente sin abandonar el estudio de ellas. Hay avances en temas particulares, nacionales y una cierta visión general del proceso intelectual de la región latinoamericana en lo que corrió desde los tiempos de la conquista hasta la década de los 19801. Uno de los temas centrales en esa historia intelectual son las redes intelectuales, que poco a poco se posiciona en el medio académico y de las referencias bibliográficas. Aunque esta perspectiva analítica de redes ha impactado en los estudios históricos desde hace décadas (principalmente en la historia económica, política y social del período colonial para el estudio de comerciantes, funcionarios y nobles), su utilización en la historia intelectual sigue siendo acotada.

1 Nos referimos a los dos tomos de la Historia de los intelectuales en América Latina dirigida por Carlos Altamirano. 
Pese al número creciente de estudios de caso que permiten entender la cantidad y el tipo de vínculos que se establecieron y que dan cuenta de la intensa circulación de ideas en un espacio trasnacional, aún no se ha adentrado en una discusión de carácter teórico y metodológico, ni menos aún se ha realizado un análisis sistemático de lo publicado hasta ahora desde una mirada historiográfica con miras a establecer tendencias interpretativas. De hecho, resta aún un debate para tener una definición consensuada de qué es una red intelectual. La más utilizada por el momento, al menos en el medio académico latinoamericano, fue la que inicialmente dio Eduardo Devés: "conjunto de personas ocupadas en la producción y difusión del conocimiento, que se comunican en razón de su actividad profesional, a lo largo de los años”, y que páginas más adelante del mismo libro vuelve a definir como "conjunto de personas ocupadas en los quehaceres del intelecto que se contactan, se conocen, intercambian trabajos, se escriben, elaboran proyectos comunes, mejoran los canales de comunicación y sobre todo establecen lazos de confianza. No hay redes productivas si no es sobre la base de la confianza recíproca ${ }^{2}$.

Aunque esta definición ha sido de gran utilidad no solo porque generó el interés de muchos investigadores en un estudio que se enfocara en los conjuntos, sus intercambios, relaciones y dimensiones trasnacionales, también plantea interrogantes. De inicio porque es necesario definir con mayor claridad quiénes son estos actores dado que pueden contraponerse a la autodefinición. Podría pensarse que lo determinante entonces no es tanto los actores, sino las acciones que realizan, pero al existir siete verbos para definirlas tampoco es evidente cuál es su importancia, ni si

2 Eduardo Devés-Valdés, Redes intelectuales en América Latina. Hacia la constitución de una comunidadintelectual (Chile: Universidad de Santiago de Chile, 2007), 30, 218. También menciona que las formas en que se relacionan sus integrantes pueden ser encuentros directos (cara a cara), indirectos (correspondencia, contactos telefónicos y a través de distintas formas: citaciones, reseñas de libros, comentarios, publicaciones, congresos y campañas). Estos contactos pueden ser esporádicos o casuales a lo largo de la vida de la red y pueden superponerse a otro tipo de relaciones (afectivas, religiosas, etc.). Aclara que la red requiere una comunicación con una determinada frecuencia o densidad a través de los núcleos (sujetos) más activos. Son, por ende, instancias no estatales que poseen elasticidad y se autogestionan. 
tales acciones o prácticas culturales e intelectuales constituyan las herramientas apropiadas para entender el comportamiento de todos los miembros de una red. Asimismo, el énfasis en los lazos de confianza recíproca causa cierta confusión al no estar plenamente problematizado. De hecho, ha sido retomado para subrayar que el análisis de redes permite entender la horizontalidad (considerada como igualdad) de las relaciones, superando la comprensión vertical que implica jerarquía e influencias (implícito en el tradicional estudio de generaciones o escuelas intelectuales) ${ }^{3}$.

Parece evidente que debe existir un interés para que una persona busque establecer un lazo, vínculo o relación, pero no necesariamente este conlleva confianza, solidaridad de manera recíproca y homogénea al interior de una red $^{4}$. Por ello, los debates en torno a las redes de sociabilidad intelectual advierten los riesgos de sobrevalorar la perspectiva sociológica de Pierre Bourdieu que enfatiza los conflictos, intereses y jerarquías del campo intelectual estudiado, complejizando, en cambio, el concepto de sociabilidad de Maurice Agulhon y George Simmel (que a su vez retoman algunos aspectos del concepto de afinidad electiva planteado por Michel Löwy), para entender la dinámica relación que existe entre el conflicto y la atracción recíproca ${ }^{5}$.

El presente dossier no pretende dar una definición alternativa de redes intelectuales, pero sí busca abrir un espacio de reflexión que continúa las preocupaciones planteadas por un grupo de

${ }^{3}$ Gemma Gordo Piñar, "El papel de las redes intelectuales en la construcción y reconstrucción del pensamiento filosófico", Bajo Palabra, Revista de Filosofía II Época, n. ${ }^{\circ} 7$ (2012): 497.

4 No obstante, Randall Collins, Sociología de las filosofias: una teoría global del cambio intelectual (Barcelona: Hacer, 2005), capítulos I y II, con mucho éxito y argumento, ha mostrado la importancia de los encuentros cara a cara, de las cargas simbólicas de la amistad, de la movilización e intercambio de capital cultural y de los lazos a través de la cultura en la formación de las redes intelectuales; realmente, en el estudio de Collins, de las redes filosóficas. Aunque, como se sabe, Collins especialmente centra su extenso estudio en lo que identifica como "cadenas de interacción" y "rituales de interacción”.

5 François Dosse, La marcha de las ideas. Historia de los intelectuales, historia intelectual (Valencia: Universidad de València, 2007), 56-58. 
investigadores de América Latina en torno a las redes intelectuales ${ }^{6}$. Para ello, en el bloque teórico y metodológico hay dos trabajos. El primero de ellos escrito por Daniel Iglesias, titulado "El aporte de las redes sociales a la historia intelectual". El autor de este trabajo retoma la categoría "redes sociales", tan cercana a la historia social y, particularmente, a la historiografía latinoamericana del periodo colonial. Iglesias sugiere que este concepto puede ser aplicado a la historia intelectual, particularmente a la historia de las redes intelectuales. Para este autor, la historia intelectual y la historia de las redes intelectuales tienen un gran potencial para comprender la movilización de "capital cultural" de un individuo, a través del análisis de fuentes documentales personales, como las memorias y, en especial, el género epistolar que se produce entre los intelectuales7. El autor argumenta sus sugerencias teóricas y metodológicas echando mano de ejemplos de intelectuales latinoamericanos que, a través de proyectos culturales y en algunos casos de carácter político, lograron establecer redes intelectuales en el espacio latinoamericanos durante la primera mitad del siglo XX.

Por su parte, Alexandra Pita González investiga en torno a "Pensar las fronteras simbólicas de una red intelectual". Reflexiona sobre las potencialidades del concepto frontera para el análisis de las redes intelectuales trasnacionales. Pita González explora ${ }^{6}$ Alexandra Pita coordinó el proyecto financiado por CONACYT del cual se publicó el libro Redes intelectuales trasnacionales en América Latina durante la entreguerra (México: Miguel Ángel Porrúa, Universidad de Colima, 2016). La mayor parte de los integrantes de este dosier participaron de ese proyecto y fue a partir de este que se planteó la necesidad de continuar la discusión abriéndolo al debate en esta revista. Por su parte, Aimer Granados coordinó un proyecto financiado por la Rectoría de la Universidad Autónoma Metropolitana, del cual surgió el libro Las revistas en la historia intelectual de América Latina: redes, intelectuales, política y sociedad, (México: UAM-Cuajimalpa, 2012).

${ }^{7}$ Cabe señalar, como en el caso de las revistas que de fuente histórica han pasado a ser objeto de investigación, sin dejar de ser lo primero, que las cartas o el género epistolar ha sufrido igualmente este "giro" investigativo. Véanse por ejemplo los dosieres de la revista Políticas de la Memoria.Anuario de investigación e información del CEDINCI, n. ${ }^{\circ}$ 14, verano 2013-2014 ("El género epistolar como desafío") y, el n ${ }^{\circ} 15$, verano 2014-2015 (“La correspondencia en la historia intelectual). 
el papel del intelectual como sujeto de frontera y lo inserta en dinámicas de carácter simbólico y cultural en aquellas otras fronteras más definidas como son las de carácter geográfico trasnacional. Pero resalta que, como agrupamientos flexibles y dinámicos, no existe un único tipo de frontera (externa) que delimita una red en función de otras redes, sino una serie de fronteras que se crean a partir de un juego de tensiones entre fuerzas de asociación y de oposición al exterior, pero también al interior, a partir de diseños que pueden llevar incluso a fracturas de la red y la creación de nuevas redes. Para observar cómo se da este proceso en una temporalidad determinada, ejemplifica con el caso - estudiado por la autora en otros trabajos- de la Unión Latino Americana y su Boletín Renovación8.

En relación con el segundo eje temático, el de los balances historiográficos, Aimer Granados se centra en el análisis de los trabajos de carácter histórico que sobre redes intelectuales se han realizado desde México. En un primer momento el autor establece la relación existente entre historia intelectual y redes intelectuales. En segunda instancia, y a partir de una base de datos sobre lo escrito y editado en México sobre redes intelectuales, el autor destaca temas y tendencias metodológicas en el estudio de este subcampo de la historia intelectual. El hilo conductor del análisis realizado por Granados consiste en agrupar los diferentes trabajos de acuerdo con ciertas binarias que el autor logra establecer a partir de sus reflexiones: 1) redes intelectuales y proyectos políticos, 2) redes intelectuales y generaciones intelectuales, 3) redes intelectuales y cultura.

El último bloque de este dosier sobre redes intelectuales lo constituye un estudio de caso escrito por Jeimy Paola Prieto, titulado "La internacionalización de una red intelectual. Revista Espiral de Artes y Letras, Bogotá 1944-1958”. A partir del estudio de la revista Espiral y del seguimiento a su principal mentor, Clemente Airó, exiliado republicano español en Colombia, la autora de este trabajo, por una parte, reconstruye la red intelectual que se forjó en torno a esta publicación y, por la otra, restituye algunas de

${ }^{8}$ Alexandra Pita, La Unión Latino Americana y el Boletín Renovación. redes intelectuales y revistas culturales en la década de 1920 (México: El Colegio de México - Universidad de Colima, 2009). 
las prácticas editoriales, de intercambio, debate y discusión que implementaron los miembros de la red intelectual agrupados en torno a Espiral. En complemento Prieto también estudia las circunstancias de enunciación y edición de esta revista en un país políticamente polarizado entre liberales y conservadores y con cierta tradición de encerramiento cultural y exaltación de valores católicos que no facilitaron los avances de la modernidad.

Como quedó sentado al inicio de esta breve introducción la historia intelectual y su indisociable tema de las redes intelectuales no ha sido muy estudiado por la historiografía latinoamericana y por lo tanto su estudio tiene un gran potencial reflexivo desde la perspectiva teórica y metodológica, así como de análisis de sus temas principales. Creemos que este dosier es una contribución que alentará nuevas investigaciones sobre estos temas.

\section{Alexandra Pita González Universidad de Colima (México)}

\section{Aimer Granados \\ Universidad Autónoma Metropolitana \\ / Cuajimalpa (México)}

Al lado de los artículos dedicados a teoría, metodología e historiografía sobre redes intelectuales, este número de Historia y Espacio adjunta tres colaboraciones de temática libre de los profesores Francisco Miguel Gimeno Blay (Universidad de Valencia, España); Luciano Arcella (Universidad del Valle, CaliColombia) y, conjuntamente, la de Álvaro Acevedo Tarazona y Juan Sebastián Bonilla Ayala (Universidad Industrial de Santander, Bucaramanga-Colombia).

La primera de ellas (Scribe ergo quee vidisti et quee sunt et quee oportet fieri post hec) reflexiona sobre las contribuciones académicas de la Paleografía y la Diplomática, inscribiéndolas en la Historia de la Cultura Escrita y demarcando sus objetivos y metodologías según los objetos a abordar y las distintas épocas históricas en que se producen, circulan y conservan. Unas 
contribuciones que, por supuesto, competen al origen y a la propia naturaleza de los documentos útiles para el estudio de nuestro pasado hispanoamericano. El profesor Gimeno Blay fue invitado al III Seminario de Cultura Escrita en Colombia dedicado al «Grafiti», seminario que desde hace tres años se celebra en la ciudad de Cali. Lamentablemente no pudo asistir, pero amablemente colaboró con el Departamento de Historia de la Universidad del Valle con esta contribución que agradecemos enormemente.

La segunda (Obsesión por la belleza. Nazismo y cultura alemana: una opción estética) estudia el movimiento nazi teniendo en cuenta los elementos significativos de la tradición cultural alemana. Se considera que el nazismo asumió la belleza como uno de los elementos que, por un lado, se tradujo en el culto a la salud, a la alimentación natural, y al amor hacia la naturaleza, pero al mismo tiempo produjo una acción de biopolítica dirigida hacia la depuración de la raza.

Por último, Una aproximación al poblamiento de la provincia Guane en las visitas de 1560 y 1572, indaga sobre la territorialidad y el poblamiento durante la segunda mitad del siglo XVI a partir de las visitas realizadas a la provincia Guane en los años 1560 y 1572. El análisis de las mismas y de los testimonios de cronistas como Castellanos, Fernández de Oviedo y fray Pedro Simón, correspondientes a este período, permiten reconocer el entorno territorial de este pueblo a partir de un estudio heurístico. Se identifican así algunas pautas de poblamiento de los guanes, el régimen de tributo impuesto en la encomienda a esta población sometida, y la variedad de productos que intercambiaban con poblaciones vecinas. 